\title{
Cognitive presence through social and teaching presence in communities of inquiry: A correlational-predictive study
}

\author{
Elba Gutiérrez-Santiuste \\ University of Córdoba, Spain \\ Clemente Rodríguez-Sabiote \\ University of Granada, Spain \\ María-Jesús Gallego-Arrufat \\ University of Granada, Spain
}

\begin{abstract}
This study focuses on the relationships established between the elements that compose the community of inquiry (CoI): cognitive, social, and teaching presence. Using three questionnaires, we analyse the students' perception of synchronous and asynchronous virtual in text-based communication (chats, forums and emails). Starting from the high correlations found between the three elements, we perform a multiple linear regression analysis. The findings show that relationships can be established in the model in which the cognitive elements are strongly predicted, to a greater extent by social presence than by teaching presence. In the forums the cognitive presence is better explained by other presences than in chats and emails. The results reveal the need to analyse the three kinds of presence jointly, assessing the impact of each on student learning. We also determine that the instructor benefits from knowing which tool is more valid for the learning objectives.
\end{abstract}

\section{Introduction}

This study describes educational virtual communication within the theoretical framework of the community of inquiry (CoI) (Garrison, Anderson, \& Archer., 2000). CoIs are grounded in the theory developed by Lipman (2003), which combines the concept of learning community with that of a social activity - the essence of the educational experience-oriented to achieving some of the best results in learning. The CoI model also shows the influence of Dewey (1933), drawing essentially on his conception of cognitive presence in the learning community.

Cleveland-Innes, Garrison, and Kinsel (2007) note that the online community of inquiry involves a public and personal search for meaning and understanding. The theoretical foundation of their approach develops their view of teaching within a constructive-cooperative framework influenced by Vygotsky (1978), which demonstrates the close relationship between personal construction of meaning and society's influence on the configuration of the educational relationship (Garrison et al., 2000). These authors also recognise the interaction between individual meaning and socially constructed knowledge. As De Leng, Dolmans, Jöbsis, Muijtjens and Van der Vleuten (2009) observe however, social activity in itself is no guarantee that higher order thinking or knowledge building will take place.

Our research (analysing synchronous and asynchronous tools) complements other studies, such as Garrison, Cleveland-Innes, and Fung (2010), which analyse the causal relationship between the presences in the model, considering the important role that teaching presence plays in establishing and maintaining the learning community. The study of Maddrell, Morrison, and Watson (2011) finds that only cognitive presence correlates significantly and positively with achievement measures. The latest research discusses a new dimension in the model, learning presence (Akyol \& Garrison, 2011; Garrison \& Akyol, 2013; Shea \& Bidjerano, 2012; Shea et al., 2012) in an attempt to explain more precisely the behaviour of students, considering metacognition in terms of self-regulation and co-regulation.

The goal of this study is to analyse the predictive relationship of cognitive presence through social and teaching presences. We analyse students' perception of the elements of the CoI model in communication in chats, forums, and emails and find consistent correlations (especially with cognitive presence) among the three communication tools. We then establish the hypothesis of the possible predictive value of social and teaching presence on cognitive presence. 


\section{Elements of the Col framework}

\section{Cognitive presence}

Cognitive presence indicates the extent to which students are capable of constructing meaning through continuous reflection in a critical research community (Garrison \& Anderson, 2003; Garrison, Anderson, \& Archer, 2001) through sustained communication (Gunawardena, Lowe, \& Anderson, 1997). Cognitive presence thus indicates the extent to which the learning objectives are achieved. The cognitive abilities involved in high-level instruction-making inferences, observing connections, verifying, and organising - generate better results when they are integrated cooperatively (Resnick, 1987), and promoted and maintained by social presence (Fabro \& Garrison, 1998; Gunawardena, 1995).

Cognitive processes and results form the core of the interactions and are defined in the CoI model as the intellectual environment that grounds the sustained critical discourse and the acquisition and application of high-level knowledge. The goal of cognitive processes is to promote the analysis, construction, and confirmation of meaning and understanding within a community of students through reflection and discourse. Integrating the public and private worlds of students is thus a basic concept in the creation of cognitive presence for educational ends. Garrison et al. (2000, 2001) define cognitive presence as the construction of meaning through sustained and permanent communication, which is achieved through greater use of group work that values the personal contribution and promotes secure learning environments to foster exchange (Matheson, Wilkinson, \& Gilhooly, 2012).

The model proposed identifies four unchanging, non-sequential phases in cognitive presence: activation (a triggering event, an evocative and inductive process), exploration, integration, and resolution (Garrison \& Anderson, 2003; Garrison et al., 2000). Activation is an integral, multifaceted process associated with a triggering event followed by deliberation, conception, and a guarantee of action.

The triggering event is a problem or dilemma that is identified or recognised through experience. Teachers' tasks or expectations often become triggering events. Garrison and Anderson (2003) argue that exploration - an inquisitive, divergent process - involves first understanding the nature of the problem and then seeking relevant information and possible explanations. Park (2009) defines exploration as exchange between the private world-reflection by the person-and the social expression of ideas. Kanuka, Rourke, and Laflamme (2007) affirm that this phase is important even though it does not represent the development of critical thinking, as it is the basis for subsequent higher levels of understanding. For Fahy (2002), students resist leaving this phase to progress to the next unless they are stimulated by the teacher. The third phase-a tentative, convergent process - is what Garrison and Anderson (2003) term integration, and it is oriented to the construction of meaning. Integration is a reflexive phase. Park (2009) indicates that integration is inferred from communication in which the teacher should diagnose misunderstanding of concepts, pose probing questions and comments, and provide additional information in order to model critical thinking. The process of integration occurs on several occasions, shifting between private reflection and public discourse (Fahy, 2002). Finally, Garrison and Anderson (2003) argue that resolution—a committed, deductive process—of the dilemma or problem yields results that usually pose new questions, activating new cycles. For Park (2009), this phase involves testing ideas and hypotheses and treating the contents from a critical perspective. For progress in this stage, it is necessary to have clear expectations, which can lead to a new problem through which the students acquire a useful key element for knowledge.

\section{Social presence}

Social presence is the capability of participants to project themselves socially and emotionally and, as real people, to promote direct communication between individuals and to make personal representation explicit (Akyol, Garrison, \& Ozden, 2009; Garrison \& Anderson, 2003). Garrison et al. (2000) indicate that social presence marks a qualitative difference between a collaborative research community and the process of merely downloading information. According to Woods and Baker (2004), research has shown that the integration of behaviors of immediacy in communication enable professors to move from mere interaction to true intimacy and interpersonal closeness through verbal and nonverbal forms. Tu and McIsaac (2002) also indicate that increasing the level of online interaction requires increasing the degree of social presence and social presence must be maintained over time (Wang \& Chen, 2013). They 
consider interaction to be one of the three dimensions of social presence, along with social context and communication.

In the CoI model, social presence is determined by affective communication, open communication, and group cohesion. Affective communication is also a characteristic of participation in a community. In the absence of visual and tonal clues, emotion can be expressed through other media, such as punctuation, capital letters, emoticons, and language itself, that is, through vocabulary and syntactical structure. Second, open communication promotes a climate of trust and acceptance. It is constructed through a process of recognition and appreciation of others' contributions, which promotes participation and interaction. For Garrison and Anderson (2003), open communication consists of generating relevant, constructive responses to the questions proposed by others. It is reciprocal and respectful, creating a climate of trust and acceptance. Third, cohesion in the CoI model is generated through open, affective communication. It must be expressed to maintain the community's commitment and goals of a learning community.

\section{Teaching presence}

Teaching presence is defined in the CoI model as the act of designing, facilitating, and orienting cognitive and social processes to obtain the results foreseen according to the students' needs and capabilities. The importance of establishing a collaborative community to generate an effective learning environment can be traced to the concept of learning based on participation in order to construct and acquire knowledge. The relationship between teachers and students constitutes the core of the educational experience. It is a complex process in which the participants have significant and complementary responsibilities. In the CoI model as developed by Garrison and Anderson (2003), we see a series of teachers' responsibilities related to design and organisation, facilitating discourse and direct teaching.

Design and organisation issues concern the macrostructure and the process. They differ in that design refers to the structural decisions adopted before the process begins, and organisation to decisions taken to adapt to changes during the educational transaction. Facilitating discourse with the goal of constructing knowledge involves recognising the role of the learning community as a promoter of the construction of meaning in which interest, motivation, commitment, and learning converge. Direct teaching is usually associated with specific issues of content, a situation in which the teacher's leadership is manifest and usually has quite a specific character. As Kupczynski, Ice, Wiesenmayer, and McCluskey (2010) indicate, this situation involves intellectual and academic leadership to provide tools that help the student to work at a higher level.

Prior research establishes a high correlation between social and cognitive presence (Shea \& Bedjerano, 2009), as well as a dynamic relation between the three presences and a causal relation of social and teaching presence to the perception of cognitive presence (Garrison et al., 2010; Archibald, 2010). These studies focus on communication through the forum. Our study expands the analysis to communication performed through chats and emails. We believe that also considering these communication tools could be interesting for education practice and research, as well as for enabling contrast of findings obtained using different methodologies to analyse the causal relationships, such as those in studies by Garrison et al. (2010) and Archibald (2010).

The research questions are:

- To what extent does social presence predict cognitive presence with the three communication tools (chats, forums, and emails)?

- To what extent does teaching presence predict cognitive presence with the three communication tools (chats, forums, and emails)?

We answer these research questions through predictive-correlational analysis of three surveys completed by the students, based on the results of studies by Garrison et al. (2010) and Archibald (2010) and taking into account the high correlation found between cognitive presence and the other two elements analysed (social and teaching presence). 


\section{Methodology}

The methodology employed in the study is that of descriptive research. More specifically, we performed a survey, followed by a correlational-predictive study. The sample consisted of 65 university students. The distribution by sex was $10.8 \%$ men to $89.2 \%$ women. The group was composed of students between the ages of 19 and $38(M=22.74, S D=3.67$, Mode $=21)$. The sample procedure used was incidental sampling. Although the sample is small for this kind of study, it includes all of the material accessible to the researchers, since the communications and chat, forum, and email activities were voluntary.

\section{Instruments}

We used different questionnaires constructed to obtain information on the students' perception of the elements of the CoI model related to each of the communication tools. The questionnaire's design was based on the CoI survey (Díaz, Swan, Ice, \& Kupczynski, 2010) but modified to incorporate other research (Arbaugh et al., 2008; Conrad, 2005; Garrison \& Anderson, 2003; Garrison et al., 2010; Haines \& Mann, 2011; Hrastinski, Keller, \& Carlsson, 2010; Picciano, 2002; Swan et al., 2008; Swan \& Shih, 2005; Tu \& McIsaac, 2002; Yen \& Tu, 2008, 2011) and to adapt the application context.

The questionnaire items correspond to the subcategories proposed in the CoI model: social presence (affect, open communication, and cohesion), cognitive presence (trigger, exploration, integration, and resolution), and teaching presence (organisation, facilitating discussion, and direct teaching). The number of items included in these categories is explained in Table 2.

The number of items in the chat questionnaire was 42, 40 items in the forum questionnaire and 12 items in the email questionnaire. Because each questionnaire was completed by the students at different points in the teaching-learning process, we considered each questionnaire independently. The items were statements to which the responses were recorded on Likert scales with either ordinal gradients or semantic differentiation. The scales had four levels - from 1 to 4 . We omitted the option of a middle response to avoid the tendency to confirmation bias (Nunnally, 1991).

The value of the scales depends on the type of item used. In scales with gradients in ordinal categories, the values are: $4=$ Strongly agree with the statement, $3=$ Agree with the statement, 2= Disagree with the statement, and 1= Strongly disagree with the statement. In scales with a semantic differential, the values are: 4= Extremely, 3= Very, 2= Somewhat, $1=$ Not at all.

To guarantee that the questionnaires were composed of items that measured the constructs for which they were conceived, we asked eight experts to review them. We were unable to perform an explanatory factor analysis (in contrast to the study by Garrison et al. 2010), because our sample contains fewer than 100 participants and because the number of participants is not five times greater than the number of variables (Comrey \& Lee 1992; McCallum, Widaman, Preacher, \& Hong 2001). We therefore decided to guarantee the construct validity of the data collection instruments using calculation of the intra-class correlation coefficient among different experts. We performed a first analysis of the intra-class correlation coefficient $(\mathrm{ICC}=.95 ; p<.000)$ and then made changes suggested by the experts to obtain a new coefficient $($ ICC $=$ $.99 ; p<.000)$.

We also calculated the reliability of the questionnaires based on the modality of internal consistency-a single test-using the Cronbach's alpha reliability coefficient. This statistic is used to observe whether the variables are consistent and stable and have a high level of correlation among themselves. We obtained the results shown in Table 1 and Table 2, separated according to constructs.

Table 1

Reliability of the questionnaires

\begin{tabular}{lcccc}
\hline \multicolumn{1}{c}{ Questionnaire } & Subjects & Excluded & Total & Cronbach’s alpha \\
\hline Chat & 65 & 0 & 65 & .876 \\
Forum & 62 & 3 & 65 & .944 \\
Email & 64 & 1 & 65 & .749 \\
\hline
\end{tabular}


From the results obtained for the Cronbach's alpha coefficients calculated, we were able to affirm that the reliability of the questionnaire on the forum was very high. This was also the case for the chat questionnaire. In both cases, reliability was confirmed using this method. Although the email questionnaire yields a lower Cronbach's alpha, the value is sufficient to guarantee reliability.

Table 2

Reliability of the three constructs

\begin{tabular}{lcccccc}
\hline \multicolumn{1}{c}{ Construct } & \multicolumn{2}{c}{ Chat questionnaire } & \multicolumn{2}{c}{ Forum questionnaire } & \multicolumn{2}{c}{ E-mail questionnaire } \\
\hline Social presence & $\begin{array}{c}\text { No. } \\
\text { items }\end{array}$ & $\begin{array}{c}\text { Cronbach’s } \\
\text { alpha }\end{array}$ & No. items & $\begin{array}{c}\text { Cronbach’s } \\
\text { alpha }\end{array}$ & No. items & $\begin{array}{c}\text { Cronbach’s } \\
\text { alpha }\end{array}$ \\
Cognitive presence & 7 & .68 & 7 & .75 & 3 & .46 \\
Teaching presence & 19 & .85 & 19 & .94 & 6 & .83 \\
Data on the student & 13 & .79 & 13 & .87 & 2 & .53 \\
\hline
\end{tabular}

\section{Procedure}

The information was collected through three questionnaires that recorded the students' perception of the communication performed in chats, forums, and emails. Two face-to-face sessions were held to explain the goals of the course, its methodology, and the synchronous and asynchronous communication instruments (text-based communications). The synchronous communications consist of 35 chats held as labs in the course Information and Communications Technology (ICT) for Education in a b-learning environment over a period of three weeks. The students were asked to analyse a series of open educational resources (videos, eBooks, blogs, forums, wikis, web pages, and reports) before the chat sessions, which were used as a place to share, discuss, and socialise. The chat sessions developed over 7 weeks. The chat sessions lasted 30 minutes each and were facilitated through 11 groups of chat rooms. One educational potential of the chat is its use as a place for debate, collective reflection, and sharing of personal opinions, and this was the purpose of the chat used for this activity. The debate focused on specific themes or topics that the students were to have prepared for debate before the chat session.

The asynchronous communications consisted of 225 forum entries and 57 emails, which were produced in the context of the same course. Emails were used to clarify students' questions and issues that only concerned one student. The forum was open for communication over a period of 3 months. Forums were then used as places to reflect, reach agreement, and summarise the ideas worked on as a group.

\section{Results}

\section{Analysis of correlations between the elements of the model}

The correlations found by considering each communication tool independently are described in Table 3.

Table 3

Correlations according to tools

\begin{tabular}{llcc}
\hline Tool & Presence & Social Presence & Teaching Presence \\
\hline Chat & Social & - & $.499^{*}$ \\
& Cognitive & $.760^{*}$ & $.608^{*}$ \\
\multirow{2}{*}{ Forum } & Social & - & $.392^{* * *}$ \\
& Cognitive & $.823^{*}$ & $.646^{*}$ \\
\multirow{2}{*}{ Email } & Social & - & $.352^{* *}$ \\
& Cognitive & $.684^{*}$ & .472 \\
\hline
\end{tabular}

$* p<.01$, two-tailed

$* * p<.05$, two-tailed.

$* * * p=.002$, two-tailed.

As one can see from the results, the highest correlations occur between social and cognitive presence, although we also obtain high correlations between cognitive and teaching presence, with weaker but statistically significant correlations between social and teaching presence. Once we confirm that the 
highest correlations occur between cognitive presence and the other forms of presence, it is advisable to calculate the multiple linear regression to try to predict the behavior of cognitive presence from social and teaching presence.

\section{Multiple linear regression analysis}

The goal of multiple linear regression analysis is to ascertain the degree to which the dependent variable - in our case, cognitive presence-can be explained by two predictor variables_-social presence and teaching presence. We performed this analysis both by considering the three tools together and by analysing each tool separately. This means that we implemented four different models, which are summarised in the multiple correlation coefficients, coefficients of determination, and standard estimation errors, as indicated in Table 4.

Table 4

Summary of the model

\begin{tabular}{lllcl}
\hline \multicolumn{1}{c}{ Tool } & $r$ & $R^{2}$ & Adjusted $R^{2}$ & $S E$ \\
\hline Three tools together & .90 & .81 & .80 & .13 \\
Chat & .80 & .64 & .63 & .17 \\
Forum & .89 & .80 & .79 & .20 \\
Email & .72 & .52 & .51 & .32 \\
\hline
\end{tabular}

For the proposed model—considering the three tools jointly-we obtained $R^{2}=.81$, which enables us to confirm that social and teaching presence predict cognitive presence for $81 \%$ of the cases; that is, the data express the proportion of variance in the dependent variable shared by the independent variables. This residual value tells us the degree of precision of the predictions: the smaller the standard error, the better the prediction, that is, the better the linear regression fits the cloud of points. Since the model is very small ( $S E=.13$ ), we can confirm that the predictions are better, as the differences between the values observed and the predictions are small. Considering each tool, we can also observe that the forums demonstrate that the independent variable explains a greater measure of the proportion of variance in the dependent variable $\left(R^{2}=.80\right)$.

Table 5

Coefficients

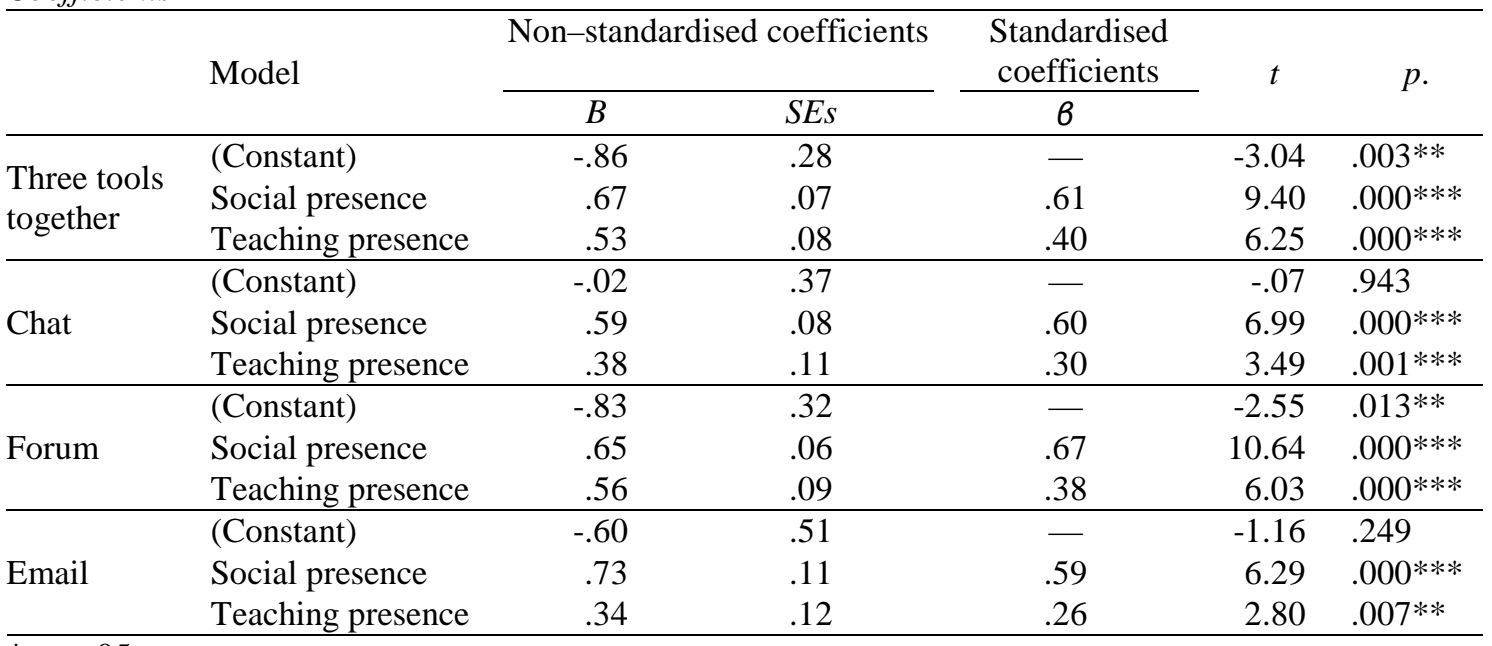

$* p<.05$

$* * p<.01$

$* * * p<.001$ 
Table 6

ANOVA

\begin{tabular}{|c|c|c|c|c|c|c|}
\hline Tool & Model & Sum of squares & $d f$ & Mean square & $F$ & $p$ \\
\hline \multirow{3}{*}{$\begin{array}{l}\text { Three tools } \\
\text { together }\end{array}$} & Regression & 5.15 & 2 & 2.57 & 131.97 & $.000 * * *$ \\
\hline & Residual & 1.21 & 62 & .02 & - & - \\
\hline & Total & 6.36 & 64 & - & - & - \\
\hline \multirow{3}{*}{ Chat } & Regression & 3.38 & 2 & 1.69 & 56.90 & $.000 * * *$ \\
\hline & Residual & 1.84 & 62 & .03 & - & - \\
\hline & Total & 5.23 & 64 & - & - & - \\
\hline \multirow{3}{*}{ Forum } & Regression & 10.18 & 2 & 5.09 & 118.28 & $.000 * * *$ \\
\hline & Residual & 2.54 & 59 & .04 & - & - \\
\hline & Total & 12.73 & 61 & - & - & - \\
\hline \multirow[t]{3}{*}{ Email } & Regression & 7.30 & 2 & 3.65 & 34.24 & $.000 * * *$ \\
\hline & Residual & 6.50 & 61 & .10 & - & - \\
\hline & Total & 13.80 & 63 & - & - & - \\
\hline
\end{tabular}

$* * * p<.001$

According to Table 6, the $F$ statistic enables us to contrast the null hypothesis that the population value of $R$ is zero. The procedure is equivalent to contrasting the hypothesis that the slope of the linear regression is 0 . This statistic permits us to determine whether there is a significant linear relationship between cognitive presence and social and teaching presences. In the case of significance for the three tools taken together, we see that, for the correlation coefficient, $R=.90$, and obtain a significant effect for regression, $F(2,62)=131.97, p=.000$. For the chat tool, the correlation value obtained is $R=.80$, with a significant effect for regression, $F(2,62)=56.90, p=.000$. In the model, the probability shows that $R$ will take the value $R=.805$. In the case of the forum tool, the resulting correlation is $R=.89$, with a significant effect for regression, $F(2,59)=118.28, p=.000$; and for email, the correlation coefficient is $R=.72$, with a significant effect for regression, $F(2,61)=34.24, p=.000$. In all cases, the ANOVAs implemented obtained variances explained by the models (source of variance for the regression) that are greater than the variances explained by the errors (source of variance of the residuals). These results, as well as the presence of a low standard error of the estimates in the four models inferred, guarantee good fit for satisfactory predictions, even though our study starts from a small sample.

In Table 5, the $B$ coefficient shows that, if the rest of the variables are kept constant and we take the three tools as a whole, an increase of one unit in social presence corresponds to an increase of $B=.67$ in cognitive presence ( $B=.59$ for chats, and $B=.73$ for email). Likewise, an increase of one unit in teaching presence corresponds to an increase of $B=.53$ in cognitive presence $(B=.56$ in the forums).

The beta coefficients may be compared directly to each other. The value obtained for social presence is 6 $=.61$, but only $B=.40$ for teaching presence. This indicates that social presence plays a greater role in the in the variation of cognitive presence. The same occurs if we observe the three tools separately (in chat $B$ $=.60$, in forums $B=.67$, and in email $B=.59$ ). For the data obtained from both the $B$ and the beta coefficients, we find that social and teaching presence are not independent of each other. The values for the $t$ and significance tests show that both social and teaching presence contribute significantly to explaining what occurs with cognitive presence, and to a greater extent with social presence $(t=9.40)$ if we take the three tools together. Since the forum yields $t=6.99$ for the chat, $t=10.64$ for social presence and $t=6.29$ for the emails, we can conclude that social presence explains cognitive presence to a greater extent than does teaching presence.

On the other hand, we consider the regression model as proposed so far to be valid based on its fulfilment of the following assumptions:

\section{Linearity}

Cognitive presence is the sum of a set of the following elements: the origin of the line, a linear combination of social and teaching presence, and residuals. In this study, the value $S E=.13$ for the total, $S E=.17$ for chat, $S E=.20$ for the forum, and $S E=.32$ for emails. The partial regression diagrams in Figures 1 and 2 show the relationship of social and teaching presence to cognitive presence. 


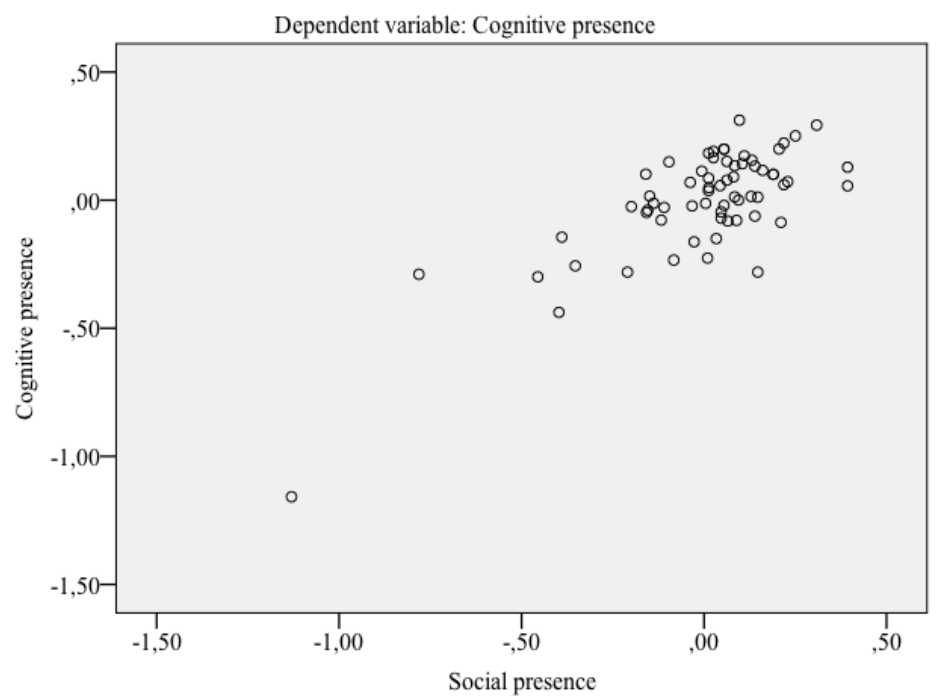

Figure 1. Graph of partial regression. Cognitive presence/social presence.

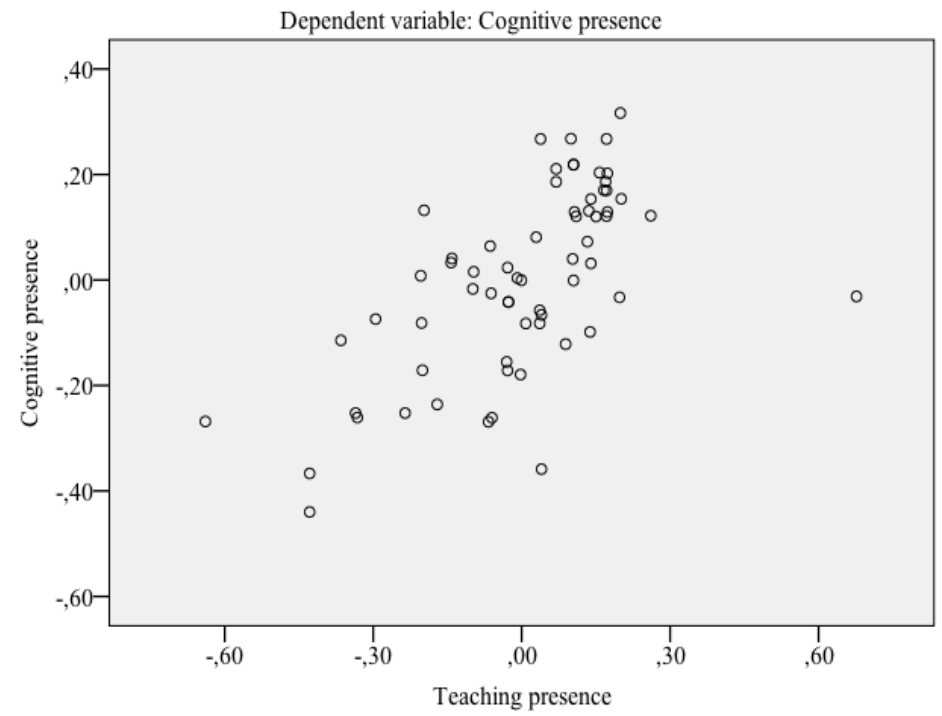

Figure 2. Graph of partial regression. Cognitive presence/teaching presence.

\section{Independence}

The residuals are independent of each other. We calculate the Durbin-Watson test, which measures the degree of self-correlation between the residual corresponding to each observation and the preceding one. If the residuals are independent, the value observed in a variable for one individual should not be influenced in any way by the values of this variable observed in the other individual. If the value of the statistic is close to 2, the residuals are not correlated; if it is close to 4 , they will be negatively selfcorrelated; and if it is close to 0, they will be positively self-correlated (Chatterjee \& Hadi, 2006). The results obtained for these statistics are as follows: a result of $(D W=1.46)$ for independence of the residuals in the case of chat, $(D W=2.02)$ in the forum, and $(D W=1.63)$ in the emails. In all cases, the values are close to 2, permitting us to affirm that the residuals are independent in the three tools; that is, they are not self-correlated. Considering the three tools together, we find that $D W=1.54$. Further, in the four cases, the associated significances occur at $\mathrm{p}>.05$, which implies acceptance of the null hypothesis and fulfillment of the assumption of independence in the four cases. 


\section{Homoskedasticity}

We used two different strategies to confirm the assumption of homoskedasticity. The first uses the values of the Durbin-Watson test (see preceding section). With Frei \& Ruloff (1989), we can affirm that homoskedasticity is fulfilled if the DW values are between 1.5 and 2.5. Since all but the first of the four cases fulfill this rule, we can say that the condition of homoskedasticity is fulfilled except in the first case. The second strategy follows Hair, Black, Babin, \& Anderson (2009) and implements a graph of the studentised residuals relative to the standardised values of the dependent variable predicted (cognitive presence). Since we chose the studentised residuals, $95 \%$ of these should be located in the interval between $\pm 2 \sigma$ to fulfill the condition of homoskedasticity (Cea D'Ancona, 2002). In our case, all but one of the points on the graph are located within this interval. We can therefore affirm that the condition of homoskedasticity is fulfilled (Figure 3).

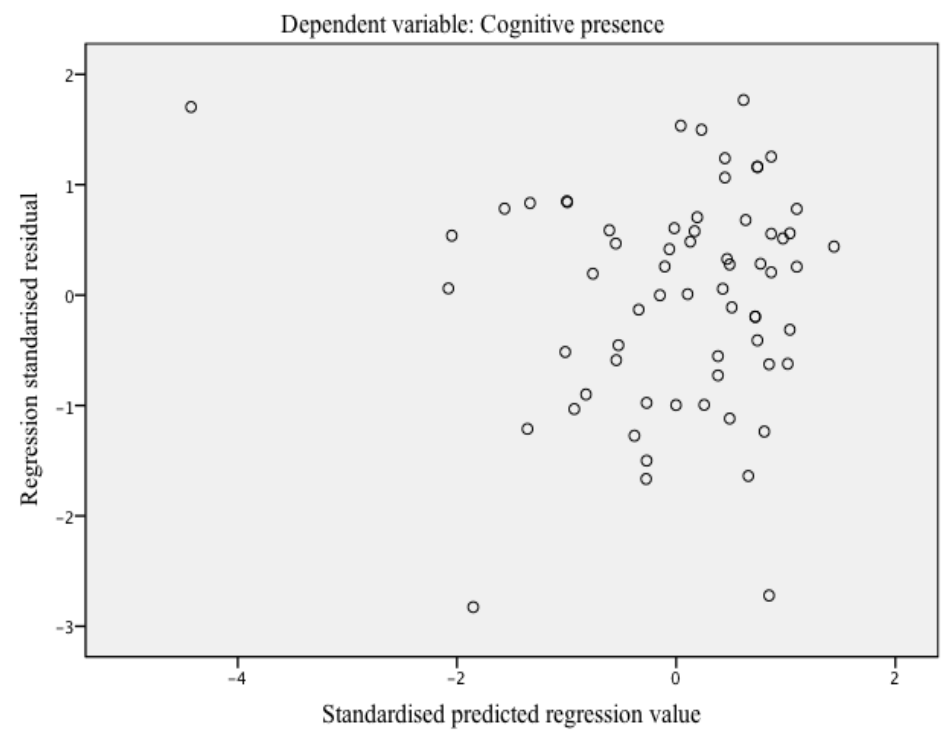

Figure 3. Graph of the dispersion, considering the three tools together.

Normality

For each value for social and teaching presence, or each combination of them, the residuals are distributed normally, with a mean of zero (Figure 4).

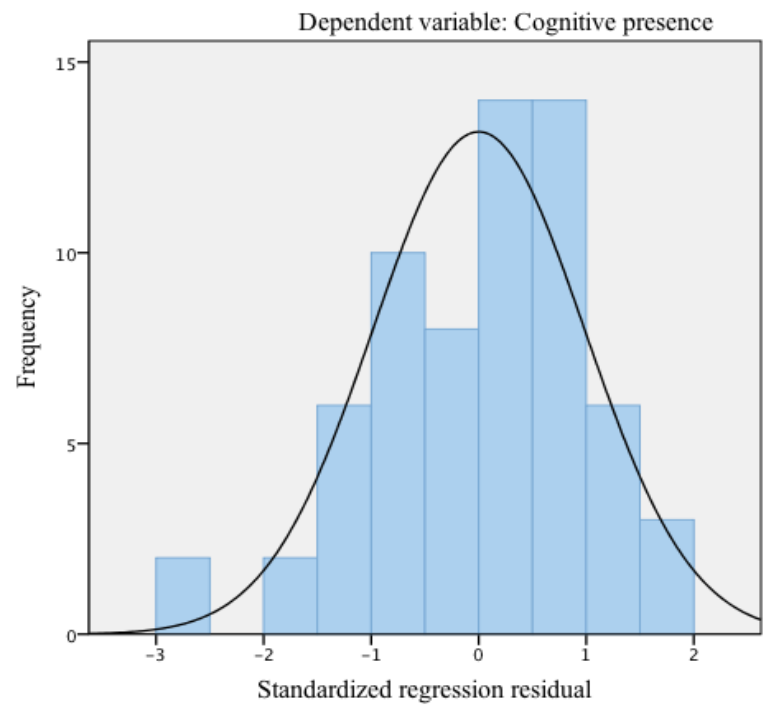

Figure 4. Histogram considering the three communication tools together.

Note: $M=1.27, S D=.984, n=65$ 
We observe a mean value close to 0 and a standard deviation close to 1 , that is, the standard situation of normality $N(0,1)$. This situation confirms that the assumption of normality is fulfilled.

\section{Non-collinearity}

There is no exact linear relationship between social and teaching presence. This result is based on the following indications, considering the three tools together: (a) the statistic $F=131.97$ is significant, and the tolerance index (.71) indicates that the variables (social and teaching presences) share $29 \%$ of their variance with the other independent variable. (b) The tolerance levels are .719 (this value is high and shows non-collinearity). (c) The inverse is low (1.39).

In the case of the chat tool: (a) the statistic $F=56.90$ is significant, and the tolerance index (.75) indicates that the variables (social and teaching presence) share $25 \%$ of their variance with the other independent variable, (b) The inverse is low (1.33). In the case of the forum tool, (a) $F=118.28$ is significant, and the tolerance index (.84) indicates that the social and teaching presence share $26 \%$ of their variance with the other independent variable, (b) The inverse is low (1.18). In the case of the email tool: (a) the statistic $F=$ 34.24 is significant, and the tolerance index (.87) indicates that social and teaching presence share $23 \%$ of their variance.

\section{Discussion and conclusions}

This study used an incidental sample, which might not be representative of online students at other institutions. Assuming a high correlation between the social, cognitive, and teaching dimensions, however, the tests of linearity, independence, homoskedasticity, and non-collinearity indicate that the current data are well suited for multiple linear regression analysis. There is an a priori limitation of small sample size, but this handicap may be mitigated in part by fulfilling the minimum number of subjects for each predictor considered in the models. Thus, there are different basic rules that establish the number of participants needed to predict. If we take into account the considerations in Green (1991) and Kelley \& Maxwell (2003) of a minimum of 10 to 15 observations per predictor, we can affirm that 65 participants for an analysis of two predictors per model provide the minimum required to implement a high-quality multiple linear regression analysis.

Our study results are consistent with other studies in several respects. The first involves the relationship between the three elements of the model and the explanation of cognitive presence through social and teaching presence. A study of Archibald (2010) indicates that 69\% of cognitive presence is explained by social and teaching presence, although our research finds a higher percentage.

Like ours, the study by Garrison et al. (2010) predicts that teaching and cognitive presence are associated with social presence, indicating that the correlation between social and cognitive presence is very high (Shea \& Bidjerano, 2009; Wanstreet \& Stein, 2011) but contrasting with the position of Annand (2011). Without using the CoI model, Liu, Gomez, and Yen (2009) conclude that social presence is a significant predictor of course retention and final grade in the community. Prior studies show the predictive relationship using forums as the medium of communication, whereas our study expands to include others_-chats and emails.

CoIs have been analysed from different perspectives, but study considers the three presences using both synchronous and asynchronous tools, finding differences in the prediction of cognitive presence as the tool used. In the forums, the cognitive dimension of communication is explained more fully by social and teaching presence than it is in chats and emails.

Virtual learning communities can orient communication to high level critical thinking and cooperation between the members, and social factors play a strong role in enabling communication oriented to the learning objectives.

The model proposed for analysis of this educational virtual communication is considered to be valid, reliable, and relevant to expanding knowledge of the triad education, communication, and virtuality. The correlations obtained confirm that the three elements are interrelated in educational communication in 
virtual environments and have different degrees of relationship between them. The student communication analysed can be considered a complex system composed of different types of relationships. These are especially consistent between the elements for learning and the social relationships established between the members of the group.

On the other hand, the findings from the regressions show that this relationship can be established in a model in which the cognitive elements-achievement of high-level learning objectives in a critical community - are strongly predicted by two elements. The first are social aspects. These aspects include issues of self-image vis à vis the other members, perceptions of others, and the relationships established between people. But a second, less significant issue, teaching action, also determines the extent to which the objectives in the educational relationship are achieved. This action includes aspects of the organisation of the educational activity, facilitation of discourse on the part of all members of the community, and the teacher's proactive role in mentoring the students.

The goal of Higher Education is to develop critical thinking, testing students' knowledge, evaluating their understanding of concepts, exploring new solutions, applying knowledge, and confirming facts. In this study, we confirm that it is necessary to attend to yet another type of issue to achieve this goal. That issue is essentially, good quality in the social relationship between the participants, achieved by means of a favorable environment that is attentive to affect, permits the members to communicate openly, and establishes group cohesion. The influence of the social and teaching elements varies, however, depending on the communication tool used. This favorable environment emerges strongly with the forum tool, to a lesser extent with the chat tool, and more weakly with the e-mail tool. In the light of the results, the findings are interesting, as we can conclude that the students' perception of good quality in the social environment will affect their perception of whether the learning objectives were achieved, due to the high value of variance in cognitive presence that is explained by social presence.

Based on the findings, we recommend that teachers who use telematic tools in their teaching activity take into account the importance both of establishing social relationships that accompany the factors considered in this study and orienting their action as organisers, leaders, tutors, and experts to achieve the learning objectives.

Social and teaching presences are related to cognitive presence (Garrison et al., 2010; Archibald, 2010). The foundation for improving learning in b-learning is students' perception. We need further study of students' perception of the elements of the CoI. Increasing the level of online interaction (Tu \& McIsaac, 2002) and moving from mere interaction to true intimacy and interpersonal closeness (Woods \& Baker, 2004) seem advisable in ICT-based learning environments.

The cognitive elements are predicted strongly, more strongly by social presence than by teaching presence. It is from this result that we derive the importance of social presence in achieving the learning objectives. Peers, climate, and relationships have more weight than teaching action. The results would probably be different in e-learning or MOOCs. It would be interesting to develop future research in this area.

We must stress that this study is limited by the small sample size used, which prevents generalisation from our results, as is also the case in the studies by Akyol \& Garrison (2011), De Leng, Dolmans, Jöbsis, Muijtjens, and Van der Vleuten (2009), and So and Brush (2008). We hope that future research will increase the amount of empirical evidence and random sampling so that we can generalise the predictive value of social and teaching presence for cognitive presence in chats, forums, and emails.

\section{References}

Akyol, Z., \& Garrison, D. R. (2011). Assessing metacognition in an online community of inquiry. Internet and Higher Education, 14(3), 183-190. doi:10.1016/ j.iheduc.2011.01.005

Akyol, Z., Garrison, D. R., \& Ozden, M. Y. (2009). Online and blended communities of inquiry: Exploring the developmental and perceptional differences. International Review of Research in Open \& Distance Learning, 10(6), 65-83.

Annand, D. (2011). Social presence within the community of inquiry framework. International Review of Research in Open and Distance Learning, 12(5), 38-54. 
Arbaugh, J. B., Cleveland-Innes, M., Díaz, S. R., Garrison, D. R., Ice, P., Richardson, J. C., \& Swan, K. P. (2008). Developing a community of inquiry instrument: Testing a measure of the community of inquiry framework using a multi-institutional sample. Internet and Higher Education, 11(3-4), 133136. doi:10.1016/ j.iheduc.2008.06.003

Archibald, D. (2010). Fostering the development of cognitive presence: Initial findings using the community of inquiry survey instrument. The Internet and Higher Education, 13(1-2), 73-74. doi: 10.1016/j.iheduc.2009.10.001

Cea D’Ancona, M. A. (2002). Análisis multivariable. Teoría y práctica en la investigación social. Madrid: Síntesis.

Chatterjee, S., \& Hadi, A. (2006). Regression analysis by example (4th ed.). New York, NY: Wiley.

Cleveland-Innes, M., Garrison, D. R., \& Kinsel, E. (2007). Role adjustment for learners in an online community of inquiry: Identifying the challenges of incoming online learners. International Journal of Web-based Learning and Teaching Technologies, 2(1), 1-16. doi:10.4018/jwltt.2007010101

Comrey, A. \& Lee, H. (1992). First course in Factor Analysis. (2nd ed.). New Jersey, NJ: Erlbaum Associates.

Conrad, D. (2005). Building and maintaining community in cohort-based online learning. Journal of Distance Education, 20(1), 1-20.

De Leng, B. A., Dolmans, D. H., Jöbsis, R., Muijtjens, A. M., \& Van der Vleuten, C. P. (2009). Exploration of an e-learning model to foster critical thinking on basics: Science concepts during work placements. Computers \& Education, 53(1), 1-13. doi:10.1016/j.compedu.2008.12.012

Dewey, J. (1933). How we think: A restatement of the relation of reflective thinking to the educative process. Boston, MA: D.C. Heath. Retrieved from http://www.gutenberg.org/files/37423/37423h/37423-h.htm

Díaz, S. R., Swan, K., Ice, P., \& Kupczynski, L. (2010). Student ratings of the importance of survey items, multiplicative factor analysis, and the validity of the community of inquiry survey. Internet and Higher Education, 13(1-2), 22-30. doi:10.1016/ j.iheduc.2009.11.004

Fabro, K. G., \& Garrison, D.R. (1998). Computer conferencing and higher-order learning. Indian Journal of Open Learning, 7(1), 41-53.

Fahy, P. (2002). Assessing critical thinking processes in a computer conference. Athabasca University. Retrieved from http:// cde.athabascau.ca/softeval/reports/mag4.pdf

Frei, D., \& Ruloff, D. (1989). Handbook of foreign policy analysis: Methods for practical application in foreign policy, planning, strategic planning and business risk assessment. Dordrecht, Netherlands: Kluwer Academic Publishers.

Garrison, D. R., \& Akyol, Z. (2013). Toward the development of a metacognition construct for communities of inquiry. Internet and Higher Education, 17, 84-89. doi:10.1016/j.iheduc.2012. 11.005

Garrison, D.R., \& Anderson, T. (2003). E-learning in $21^{\text {st }}$ century: A framework for research and practice. London: Routledge Falmer.

Garrison, D. R., Anderson, T., \& Archer, W. (2000). Critical inquiry in a text-based environment: Computer conferencing in higher education. Internet and Higher Education, 11(2), 1-14. doi:10.1016/S1096-7516(00)00016-6

Garrison, D. R., Anderson, T., \& Archer, W. (2001). Critical thinking, cognitive presence, and computer conferencing in distance education. The American Journal of Distance Education, 15(1), 7-23.

Garrison, D. R., Cleveland-Innes, M., \& Fung, T. S. (2010). Exploring causal relationships among teaching, cognitive and social presence: Student perceptions of the community of inquiry framework. The Internet and Higher Education, 13(1-2), 31-36. doi:10.1016/j.iheduc.2009.10.00

Green S. B. (1991). How many subjects does it take to do a regression analysis? Multivariate Behavioral Research, 26(3), 499-510.

Gunawardena, C. N. (1995). Social presence theory and implications for interaction and collaborative learning in computer conference. International Journal of Educational Telecommunications, 1(2-3), 147-166. Taiwan. Retrieved from http://www.360doc.com/content/07/0525/12/18017_519886.shtml

Gunawardena, C. N., Lowe, C. E., \& Anderson, T. (1997). Analysis of a global online debate and the development of an interaction analysis model for examining social construction of knowledge in computer conferencing. Journal of Educational Computing Research, 17(4), 397-431.

Haines, R., \& Mann, J. E. (2011). A new perspective on de-individuation via computer-mediated communication. European Journal of Information Systems: An Official Journal of the Operational Research Society, 20(2), 156-167. doi:10.1057/ejis.2010.70

Hair, J., Black, W., Babin, B., \& Anderson, R. (2009). Multivariate Data Analysis (7th ed.). New York, NY: Pearson. 
Hrastinski, S., Keller, C., \& Carlsson, S. A. (2010). Design exemplars for synchronous e-learning: A design theory approach. Computers \& Education, 55(2), 652-662. doi:10.1016/ j.compedu.2010.02.025

Kanuka, H., Rourke, L., \& Laflamme, E. (2007). The influence of instructional methods on the quality of online discussion. British Journal of Educational Technology, 38(2), 260-271. doi:10.1111/j.14678535.2006.00620.x

Kelley, K., \& Maxwell, S. E. (2003). Sample size for Multiple Regression: Obtaining regression coefficients that are accuracy, not simply significant. Psychological Methods, 8(3), 305-321.

Kupczynski, L., Ice, P., Wiesenmayer, R., \& McCluskey, F. (2010). Student perceptions of the relationship between indicators of teaching presence and success in online courses. Journal of Interactive Online Learning, 9(1), 23-43.

Lipman, M. (2003). Thinking in education (2nd ed.). Cambridge, UK: Cambridge University Press.

Liu, S. Y., Gomez, J., \& Yen, C. J. (2009). Community college online course retention and final grade: Predictability of social presence. Journal of Interactive Online Learning, 8(2), 165-182.

Maddrell, J. A., Morrison, G. R., \& Watson, G. S. (2011, November). Community of inquiry framework and learner achievement. Paper presented at the Annual Meeting of the Association of Educational Communication \& Technology, Jacksonville, FL. Retrieved from http://www.jennifermaddrell.com/wp-content/uploads/2011/11/MADDRELL-MORRISONWATSON-AECT-Featured-Research-Paper-FINAL-20111110.pdf

Matheson, R., Wilkinson, S. C., \& Gilhooly, E. (2012). Promoting critical thinking and collaborative working through assessment: Combining patchwork text and online discussion boards. Innovations in Education and Teaching International, 49(3), 257-267. doi:10.1080/14703297.2012.703023

McCallum, R., Widaman, K., Preacher, K., \& Hong, S. (2001). Sample size in factor analysis: the role of model error. Multivariate Behavioral Research. 36(4), 611-637.

Nunnally, J. C. (1991). Teoría psicométrica. Mexico: Trillas.

Park, C. L. (2009). Replicating the use of a cognitive presence measurement tool. Journal of Interactive Online Learning, 8(2), 140-155.

Picciano, A. G. (2002). Beyond student perceptions: Issues of interaction, presence, and performance in an online course. Journal of Asynchronous Learning Networks, 6(1), 21-40.

Resnick, L. B. (1987). Education and learning to think. Washington, WA: National Academy Press.

Shea, P., \& Bidjerano, T. (2009). Community of inquiry as a theoretical framework to foster "epistemic engagement” and "cognitive presence” in online education. Computers \& Education, 52(3), 543-553. doi:10.1016/j.compedu.2008.10.007

Shea, P., \& Bidjerano, T. (2012). Learning presence as a moderator in the community of inquiry model. Computer \& Education, 59(2), 316-326. doi:10.1016/ j.compedu.2012.01.011

Shea, P., Hayes, S., Smith, S. U., Vickers, J., Bidjerano, T., Pickett, A., ... Jian, S. (2012). Learning presence: Additional research on a new conceptual element within the Community of Inquiry (CoI) framework. Internet and Higher Education, 15(2), 89-95. doi:10.1016/j.iheduc.2011.08.002

So, H.J., \& Brush, T.A. (2008). Student perceptions of collaborative learning, social presence and satisfaction in a blended learning environment: Relationship and critical factors. Computer \& Education, 51, 318-336. doi:10.1016/j.compedu.2007.05.009

Swan, K. P., Richardson, J. C., Ice, P., Garrison, D. R., Cleveland-Innes, M., \& Arbaugh, J. B. (2008). Validating a measurement tool of presence in online communities of inquiry. e-mentor, 2(24), 1-12. Retrieved from http://www.ementor.edu.pl/e_index.php?numer=24\&all=1

Swan, K., \& Shih, L. F. (2005). On the nature and development of social presence in online course discussions. Journal of Asynchronous Learning Networks, 9(3), 115-136.

Tu, C. H., \& McIsaac, M. (2002). The relationship of social presence and interaction in online classes. American Journal of Distance Education, 16(3), 131-150. doi:10.1207/S15389286AJDE1603_2

Vygotsky, L. (1978). Mind in society. Cambridge, MA: Harvard University Press.

Wang, M.-J, \& Chen, H.C. (2013). Social presence for different tasks and perceived learning in online hospitality culture exchange. Australasian Journal of Educational Technology, 29(5), 667-684. Retrieved from http://ascilite.org.au/ajet/submission/index.php/AJET/article/view/215

Wanstreet, C. E., \& Stein, D. S. (2011). Presence over time in synchronous communities of inquiry. American Journal of Distance Education, 25(3), 162-177. doi:10.1080/ 08923647.2011.590062

Woods, R. H., \& Baker, J. D. (2004). Interaction and immediacy in online learning. The International Review of Research in Open and Distance Learning, 5(2), 1-13.

Yen, C., \& Tu, C. (2008). Online social presence: A study of score validity of the computer-mediated communication questionnaire. Quarterly Review of Distance Education, 9(3), 297-310. 
Yen, C., \& Tu, C. (2011). A multiple-group confirmatory factor analysis of the scores for online social presence: Do they measure the same thing across cultural groups? Journal of Educational Computing Research, 44(2), 219-242.

Corresponding author: Elba Gutiérrez-Santiuste, egutierrez@uco.es

Australasian Journal of Educational Technology (c) 2015.

Please cite as: Gutiérrez-Santiuste, E., Rodríguez-Sabiote, C., \& Gallego-Arrufat, M-J. (2015). Cognitive presence through social and teaching presence in communities of inquiry: A correlational-predictive study. Australasian Journal of Educational Technology, 31(3), 349-362. 